\title{
Combination of Two Mutant Alpha Spectrin Alleles Underlies a Severe Spherocytic Hemolytic Anemia
}

\author{
Hynek Wichterle, ${ }^{\star}$ Manjit Hanspal, ${ }^{\star}$ Jiri Palek, ${ }^{\star}$ and Petr Jarolim ${ }^{\star \S}$ \\ *Department of Biomedical Research, St. Elizabeth’s Medical Center, Boston, Massachusetts 02135; ${ }^{*}$ The Rockefeller University, \\ New York 10021; and ${ }^{\S}$ Institute of Hematology and Blood Transfusion, 12820 Prague, Czech Republic
}

\begin{abstract}
We studied a patient with a severe spherocytic hemolytic anemia without family history of spherocytosis. Analysis of patient's erythrocyte membrane proteins revealed spectrin deficiency and a truncated $\alpha$ spectrin protein. We determined that the patient is a compound heterozygote with two mutations in $\alpha$ spectrin gene. Mutation in the paternal allele, designated $\alpha$ spectrin $^{\text {PRAGUE }}$, is a transition $A$ to $G$ in the penultimate position of intron 36 that leads to skipping of exon 37, frameshift, and production of the truncated $\alpha$ spectrin protein. The maternal allele, designated $\alpha$ spectrinLEPRA, contains transition $C \rightarrow T$ in position -99 of intron 30 . This mutation enhances an alternative acceptor splice site 70 nucleotides upstream from the regular site. The alternative splicing causes a frameshift and premature termination of translation leading to a significant decrease in $\alpha$ spectrin production. The $\alpha^{\text {LEPRA }}$ mutation is linked to a spectrin $\alpha$ IIa marker that was found to be associated with recessive or nondominant spectrin-deficient hereditary spherocytosis in $\sim 50 \%$ of studied families. We conclude that the $\alpha^{\text {LEPRA }}$ mutation combined in trans with the $\alpha^{\text {PRAGUE }}$ mutation underlie the severe hemolytic anemia in the proband. We suggest that allele $\alpha$ spectrin $^{\text {LEPRA }}$ may be frequently involved in pathogenesis of recessive or nondominant spectrin-deficient hereditary spherocytosis. (J. Clin. Invest. 1996. 98:23002307.) Key words: congenital hemolytic anemia - DNA mutational analysis - messenger RNA - alternative splicing • protein synthesis
\end{abstract}

\section{Introduction}

Hereditary spherocytosis (HS $)^{1}$ is an inherited hemolytic anemia characterized by the presence of spherical erythrocytes in

This work was presented in part as abstract 1857 at the 37 th meeting of the American Society of Hematology, Seattle, WA, 1-5 December 1995.

Address correspondence to Petr Jarolim, Department of Pathology, Brigham and Women's Hospital, Harvard Medical School, 75 Francis Street, Boston, MA 02115. Phone: 617-732-4725; FAX: 617277-9013; E-mail: pjarolim@bics.bwh.harvard.edu

Received for publication 18 July 1996 and accepted in revised form 17 September 1996.

1. Abbreviations used in this paper: HS, hereditary spherocytosis; LEPRA, low expression allele Prague; nt, nucleotide; r/ndHS, recessive nondominant HS; SSCP, single-strand conformational polymorphism.

J. Clin. Invest.

(C) The American Society for Clinical Investigation, Inc. 0021-9738/96/11/2300/08 \$2.00

Volume 98, Number 10, November 1996, 2300-2307 peripheral blood smears and increased osmotic fragility of red blood cells(RBC). The disease prevalence is highest in Northern Europe where it affects $\sim 0.02 \%$ of population. The molecular basis of HS is heterogeneous, with primary defects in several proteins of the erythrocyte membrane skeleton, a twodimensional flexible network of spectrin and other proteins laminating the cytoplasmic side of RBC plasma membrane. Several groups identified mutations in band 3 protein (1-7), ankyrin (7-10), and $\beta$ spectrin (11-15) associated mostly with autosomal dominant HS, and in protein 4.2 (16-20) associated mostly with mild to moderate recessive (r) or nondominant (nd) HS.

Besides the typical autosomal dominant HS and the relatively rare, recessive, protein 4.2-deficient HS, Agre and colleagues identified a subset of patients affected by a more severe anemia inherited in an autosomal recessive or nondominant pattern (r/ndHS) (21-23). Clinical severity of this type of anemia was proportional to a degree of spectrin deficiency, ranging from $53 \%$ of normal spectrin content in severely anemic patients to $31 \%$ of normal in nearly lethal cases (22). Analysis of red cell membrane proteins isolated from $\mathrm{r} / \mathrm{ndHS}$ patients demonstrated that in $\sim 50 \%$ cases the disease was linked to an $\alpha$ spectrin variant $\alpha \mathrm{II}$, whose prevalence in the normal population ranges from 2 to $7 \%$ (24-27). This linkage disequilibrium indicates that the $\alpha$ spectrin allele carrying the $\alpha$ IIa mutation plays a role in the pathogenesis of $r / n d H S$, but there is no direct evidence that the mutation itself has any effect on the phenotype (28).

Spectrin, the predominant constituent of RBC membrane skeleton, is a filamentous protein composed of two subunits: $\alpha$ spectrin $(281 \mathrm{kD})$ and $\beta$ spectrin $(246 \mathrm{kD})$. The formation of the spectrin heterodimer starts by primary interaction of the two subunits at nucleation sites localized in $\alpha \mathrm{V}(\mathrm{COOH}$-terminal) and $\beta \mathrm{IV}\left(\mathrm{NH}_{2}\right.$-terminal) domains and proceeds by zipping the two chains together in antiparallel manner (29). The $\alpha$ spectrin is synthesized in more than twice the amount of $\beta$ spectrin during maturation of mammalian erythrocytes $(30,31)$, suggesting that in the majority of cases both $\alpha$ spectrin alleles have to be mutated to produce an abnormal RBC phenotype.

This report represents an initial attempt to define molecular basis underlying the spectrin deficiency in patients with r/ndHS. We studied one subject heterozygous for $\alpha$ IIa mutation and affected by the disease. We present two mutations identified in the $\alpha$ spectrin gene that very likely account for patient's phenotype. In addition we suggest that the mutation found in cis with the $\alpha$ IIa marker may represent a defect frequently involved in pathogenesis of spectrin deficient r/ndHS.

\section{Methods}

Case report. The proband was splenectomized at the age of 6 because of a severe spherocytic hemolytic anemia. Basic hematological parameters are shown in Table I. In addition, before splenectomy, the 
Table I. Basic Hematological Parameters of the Studied Subjects

\begin{tabular}{|c|c|c|c|c|c|c|c|c|}
\hline & $\begin{array}{l}\text { Date of } \\
\text { birth }\end{array}$ & Splenectomy & Hemoglobin & Hematocrit & MCV & RDW & Retics & $\begin{array}{l}\text { Osmotic } \\
\text { fragility }\end{array}$ \\
\hline & & & $g / d l$ & $\%$ & $f l$ & $\% *$ & $\%$ & \\
\hline \multirow[t]{2}{*}{ Proband } & 1985 & & 8.5 & 23.0 & 80.0 & & 13.4 & $0.76-0.36$ \\
\hline & & 1991 & $15.2^{\S}$ & $44.0^{\S}$ & $84.8^{\S}$ & $13.9^{\S}$ & $3.1^{\S}$ & $0.70-0.38^{\S}$ \\
\hline Father & 1960 & No & 15.2 & 46.0 & 84.9 & 12.2 & 1.0 & $0.46-0.32$ \\
\hline Mother & 1965 & No & 14.7 & 44.0 & 90.4 & 12.6 & 1.2 & $0.47-0.34$ \\
\hline
\end{tabular}

* Normal range $11.5-14.5$. ${ }^{*}$ Osmotic fragility is given as an interval between minimum osmotic resistance (normal range $\left.0.48-0.44\right)$ and complete hemolysis (normal $0.34-0.30$ ). ${ }^{\S}$ Data after splenectomy.

proband was subicteric with total bilirubin $2.9 \mathrm{mg} / \mathrm{dl}$. Autohemolysis without glucose was $13.1 \%$, with glucose $7.9 \%$, spleen was palpable 3 $\mathrm{cm}$ over the costal margin, and bone marrow aspirate revealed a marked hyperplasia of the erythroid lineage that comprised $50.4 \%$ of total bone marrow cellularity. After splenectomy, the patient had normal red cell count; however, his reticulocyte count remained elevated and osmotic fragility remained increased. Patient's peripheral blood smear contained numerous spherocytes and microspherocytes. There is no family history of spherocytosis and the hematological parameters as well as red cell morphology of both parents are normal.

Membrane protein analysis. Freshly drawn blood anticoagulated in acid citrate/dextrose was shipped on ice from Prague to Boston. The blood samples were processed within $48 \mathrm{~h}$ of phlebotomy. Erythrocyte ghosts were prepared by the method of Dodge et al. (32). Proteins were analyzed by SDS-PAGE in $3.5-17 \%$ gradient gels according to Agre's modification (22) of the original Fairbanks method (33) and in $12 \%$ Laemmli gels (34). The relative abundance of the major red cell membrane proteins was analyzed, using the Eagle Eye II system (Stratagene, La Jolla, CA) and the ONE-Dscan 1.0 program (Scanalytics, Billerica, MA). For immunoblotting, the electrophoresed proteins were transferred to a nitrocellulose membrane, incubated with rabbit anti-human $\alpha$ spectrin antiserum, peroxidase-conjugated goat anti-rabbit antibody (Sigma Chemical Co., St. Louis, $\mathrm{MO})$ and visualized by chloronaphtol staining. For quantitation of band 3 by flow cytometry, washed RBC were incubated with eosin5-maleimide (Molecular Probes Inc., Eugene, OR) and analyzed using a flow cytometer (PROFILE II; Coulter Electronics, Hialeah, FL) as described $(2,35)$. For study of the spectrin oligomerization state, spectrin was extracted and the percentage of spectrin dimers was calculated from densitometric tracing of nondenaturing tube gels as described (36).

cDNA analysis. Total reticulocyte RNA was isolated by ammonium chloride lysis (37) and reverse-transcribed using random primers. The structure of $\alpha$ spectrin cDNA was analyzed by PCR amplification of overlapping segments with primers derived from $\alpha$ spectrin sequence (38). To study the aberrant exon 37 region, cDNA from the proband and a control subject were PCR amplified using primers SA39 (5'-CCTATGCCTTGTTCCAGTTC-3'; within exon 36) and 405 (5'-GGATGTCTTCTCCTTGTGCA-3'; within exon 40) (30 cycles; $10 \mathrm{~s}$ at $96^{\circ} \mathrm{C}, 1 \mathrm{~min}$ at $64^{\circ} \mathrm{C}$, and $30 \mathrm{~s}$ at $72^{\circ} \mathrm{C}$ ). An aliquot of the PCR product was cloned into plasmid pCR II using the TA Cloning Kit (Invitrogen, San Diego, CA). One clone of the expected size and one clone containing the truncated cDNA were sequenced using the Sequenase Version 2.0 DNA Sequencing Kit (U.S. Biochemical Corp., Cleveland, $\mathrm{OH}$ ) and a sequencing primer SA39. To analyze the aberrant exon 30 region, cDNA was PCR amplified using primers SA9 (5'-AGAGGACTTCAGTGCAGAAC-3'; within exon 29) and SA10 (5'-CCTGTCTAGTACACGTTGGA-3'; within exon 31) in the DNA Thermal Cycler (Perkin-Elmer Cetus, Norwalk, CT) programmed for 35 cycles $\left(10 \mathrm{~s}\right.$ at $96^{\circ} \mathrm{C}, 30 \mathrm{~s}$ at $64^{\circ} \mathrm{C}$, and $10 \mathrm{~s}$ at $72^{\circ} \mathrm{C}$ ). An aliquot of the product was cloned into plasmid; one clone of the expected size and one clone containing the larger cDNA were sequenced using a sequencing primer SA10 as described above. To ana- lyze the alternative splicing, the two isoforms were separated on $1.5 \%$ agarose minigel $(30 \mathrm{~min}, 110 \mathrm{~V})$. The gel was stained with ethidium bromide and the relative abundance of the isoforms was analyzed by densitometry as described above. To study the $\alpha$ IIa mutation, cDNA was PCR amplified using primers SA29 (5'-ATGAGGCCTTTCTATTAGATC-3'; within exon 20) and K2 (5'-AGCTGGGACAATGCCCTGAT-3'; within exon 22) $\left(40\right.$ cycles; $10 \mathrm{~s}$ at $96^{\circ} \mathrm{C}, 30 \mathrm{~s}$ at $64^{\circ} \mathrm{C}$, and $10 \mathrm{~s}$ at $72^{\circ} \mathrm{C}$ ). The PCR product was ethanol precipitated, resuspended in water, digested with restriction endonuclease FokI and analyzed on $2 \%$ agarose gel.

Genomic DNA analysis. Genomic DNA was isolated from the proband as described (39). To investigate the exon 37 skipping event, the genomic DNA was PCR amplified using primers SA39 and SA40 (5'-ATCTCCTCTTGCCCCACAGC-3'; within exon 38) (35 cycles; $10 \mathrm{~s}$ at $98^{\circ} \mathrm{C} ; 1 \mathrm{~min}$ at $60^{\circ} \mathrm{C}$; and $4 \mathrm{~min}$ at $68^{\circ} \mathrm{C}$ ). The PCR product was cloned as described above and six clones together with genomic DNA from the proband and his parents were PCR amplified using primers SA41 (5'-AAGCTATTGCTGTAGGATGAC-3'; within intron 36) and SA18 (5'-GGATGGCAGGCTCATGGG-3'; within exon 37) $\left(25\right.$ cycles; $10 \mathrm{~s}$ at $96^{\circ} \mathrm{C}, 30 \mathrm{~s}$ at $64^{\circ} \mathrm{C}$, and $1 \mathrm{~s} \mathrm{at} 72^{\circ} \mathrm{C}$ ) and screened for single-strand conformational polymorphism (SSCP) on $10 \%$ glycerol MDE gel (AT Biochem, Malvern, PA) as described $(2,40)$. The mutant and the normal clone were sequenced as described above, using nested sequencing primer SA18. To study the alternative splicing of intron 30, proband's genomic DNA was PCR amplified using primers SA45 (5'-TGATGAAGAAACGGGACGAT-3'; within exon 30) and SA10 $\left(35\right.$ cycles; $10 \mathrm{~s}$ at $95^{\circ} \mathrm{C}, 30 \mathrm{~s}$ at $60^{\circ} \mathrm{C}$, and $2 \mathrm{~min}$ at $\left.68^{\circ} \mathrm{C}\right)$. The PCR product was cloned and 4 individual and 20 pooled clones were sequenced as described above, using sequencing primers SA42 (5'-AAGAGCCCAGCTGCTTGGAG-3', within alternatively spliced part of intron 30). To screen subjects for the mutation introducing EcoRI site, genomic DNA was PCR amplified using primers SA55 (5'-GACCTCAAGTGATCTACCT-3'; within intron 30) and SA10 ( 35 cycles; $10 \mathrm{~s}$ at $96^{\circ} \mathrm{C}, 30 \mathrm{~s}$ at $60^{\circ} \mathrm{C}$, and $30 \mathrm{~s}$ at $72^{\circ} \mathrm{C}$ ) and the PCR product was digested with restriction endonuclease EcoRI and analyzed on $1.5 \%$ agarose gel.

Study of spectrin synthesis in erythroblasts. Erythroblasts were prepared from peripheral blood in a two-phase liquid culture system as described $(31,41)$. An aliquot of erythroblasts was metabolically labeled for $60 \mathrm{~min}$ with $\left.{ }^{35} \mathrm{~S}\right]$ methionine. The soluble (cytoplasmic) and insoluble (membrane) fractions were separated, spectrin was immunoprecipitated using polyclonal antispectrin antibodies, electropho-resed in $8 \%$ Laemmli gel, and the gel was dried and exposed to Hyperfilm (Amersham Corp., Arlington Heights, IL). The intensity of the $\alpha$ and $\beta$ spectrin bands was analyzed by densitometry as described above.

\section{Results}

Biochemical characterization of membrane proteins. To determine defects underlying the severe spherocytic anemia diagnosed in the patient, we analyzed RBC membrane proteins isolated from the patient, his parents, and a control subject on 

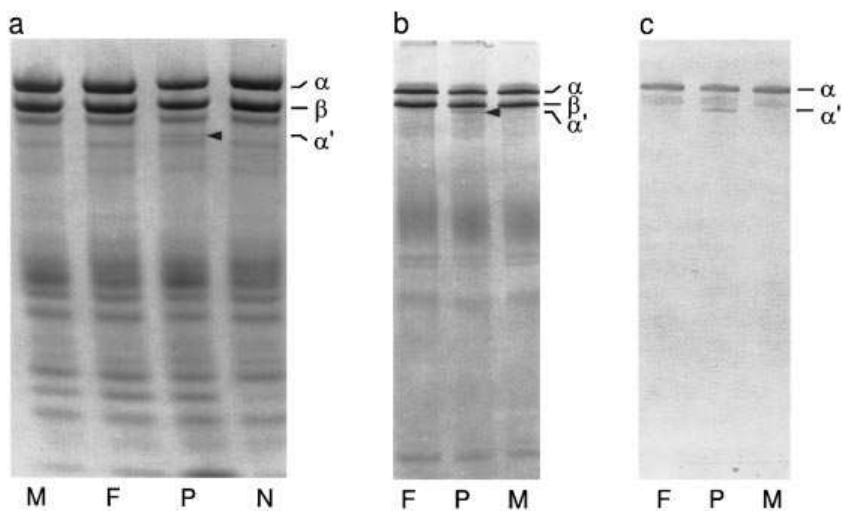

Figure 1. Electrophoretic analysis of RBC membrane proteins. Coomassie blue-stained erythrocyte membrane proteins from the proband $(P)$, his parents $(M, F)$ and a normal subject $(N)$ were electrophoresed $(a)$ in the $3.5-17 \%$ exponential gradient polyacrylamide gel and $(b)$ in $12 \%$ Laemmli gel. Both gel systems reveal presence of an abnormal band designated as $\alpha^{\prime}$ (arrowhead). (c) Western blot of the gel in $(b)$ shows immunoreactivity of the truncated band with polyclonal anti- $\alpha$ spectrin antibodies.

the Fairbanks and Laemmli SDS-PAGE. The analysis revealed the presence of an additional band of apparent molecular mass of $\sim 195 \mathrm{kD}$ in proband's membranes (Fig. 1, $a$ and $b$ ). On Western blots the protein reacted with antibodies against $\alpha$ spectrin (Fig. $1 c$ ) but did not react with antibodies against $\beta$ spectrin or ankyrin. The band, designated as $\alpha^{\prime}$ spectrin, constituted $\sim 4 \%$ of total $\alpha$ spectrin. In addition to the truncated protein detected in proband, densitometric tracing of Fairbanks gels revealed an $\sim 34 \%$ decrease in the spectrin to band 3 ratio and an $\sim 27 \%$ decrease in the ankyrin to band 3 ratio in patient's membrane skeleton. Measurement of the relative number of band 3 copies per cell by flow cytometry revealed a decrease in the band 3 content to $70 \%$ of normal. This result allowed us to correct the relative spectrin to band 3 ratio obtained by gel densitometry and to estimate the actual spectrin content in proband's erythrocytes as $\sim 46 \%$ of normal (Table II). Functional study of the spectrin dimer-dimer association site by separation of spectrin dimers, tetramers, and oligomers on nondenaturing gel revealed normal ratio of dimers and tetramers (data not shown).

Splice site mutation in paternal allele. To identify the molecular defect responsible for the truncation of $\alpha$ spectrin protein, we analyzed structure of proband's $\alpha$ spectrin mRNA. Amplification and agarose gel analysis of a region spanning exon 37 revealed a doublet in the proband and in his father and a single band in his mother and in five control subjects. The single band of the expected size corresponded to the longer band in the doublet. Cloning and sequencing of the shorter fragment showed that the entire exon 37 was missing from the mRNA (data not shown).

To determine the basis of the aberrant splicing event, proband's genomic DNA spanning intron 36, exon 37, and intron 37 was PCR amplified, cloned, and the clones together with proband's and his parents' genomic DNA were screened for an SSCP in exon-intron boundaries. Sequencing of the polymorphic intron 36-exon 37 boundary revealed an A to G transition at the penultimate position of the acceptor splice site upstream of exon 37: ttgattttag/GGA to ttgattttgg/GGA (Fig.

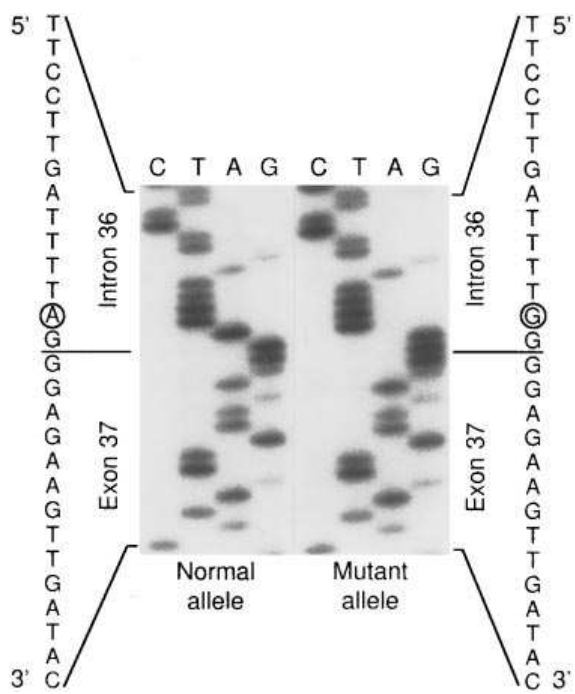

Figure 2. Nucleotide sequences of intron 36-exon 37 junction corresponding to the normal $\alpha$ spectrin allele and to the mutated paternal allele. Sequences of two different subclones derived from proband's genomic DNA are shown. The nucleotide in -2 position of the acceptor splice site of intron 36, mutated in the paternal allele, is circled.

2). The same mutation was identified in father's genomic DNA. Schematic representation of the defective allele designated as $\alpha$ spectrin $^{\text {PRAGUE }}$ and the ensuing aberrant splicing leading to a frameshift and premature termination of translation is shown in Fig. 3. 700 amino acid residues from $\alpha$ spectrin $\mathrm{COOH}$ terminus (corresponding to a half of the $\alpha \mathrm{IV}$ and the entire $\alpha \mathrm{V}$ domains) are replaced by eight new amino acids (MCWIWQRS) in the putative truncated protein. The calculated molecular mass of the protein $(202 \mathrm{kD})$ corresponds well to the apparent molecular mass deduced from electrophoretic mobility of the $\alpha^{\prime}$ spectrin detected in subject's RBC membranes $(\sim 195 \mathrm{kD})$.

Aberrant alternative splicing in the maternal allele. Detection of one $\alpha$ spectrin $^{\text {PRAGUE }}$ allele in the asymptomatic father suggested that the mutation is recessive. Since the propositus is also heterozygous for this recessive mutation, we searched for an additional $\alpha$ spectrin gene defect, which would explain the subject's spherocytic phenotype. PCR amplification and agarose gel analysis of a region spanning exon 30 revealed a doublet with a shorter band of the expected size (Fig. 4). Cloning and sequencing of the longer fragment demonstrated that 70 nucleotides (nt) from the $3^{\prime}$ end of intron 30 were inserted into

Table II. Quantitation of Red Cell Membrane Proteins Expressed in Percentages of Control Values

\begin{tabular}{lccccc}
\hline & $\alpha$ Sp/ $\beta$ Sp* & Sp/B3 & $2.1 / \mathrm{B} 3$ & B3/cell $^{\ddagger}$ & Sp/cell $^{\S}$ \\
\hline & $\%$ & $\%$ & $\%$ & $\%$ & \\
Proband & 93 & 66 & 73 & 70 & 46 \\
Father & 101 & 97 & 93 & 95 & 92 \\
Mother & 99 & 100 & 98 & 92 & 92 \\
& & & & & \\
\hline
\end{tabular}

Sp, spectrin; B3, band 3; 2.1, ankyrin isoform 2.1. * $\alpha$ spectrin in the proband includes the truncated $\alpha^{\prime}$ spectrin $\left(\alpha^{\prime}\right.$ contains $4 \%$ of $\alpha$ spectrin). ${ }^{*}$ Band 3 content per cell measured by flow cytometry. ${ }^{8} \mathrm{Sp} / \mathrm{B} 3$ ratio corrected for the band 3 content per cell. 


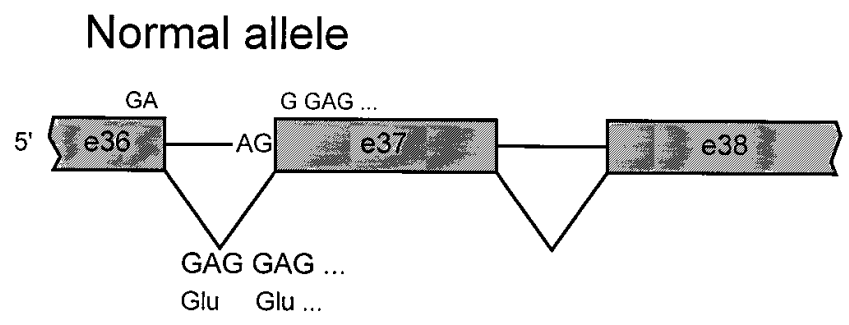

\section{Mutant allele}

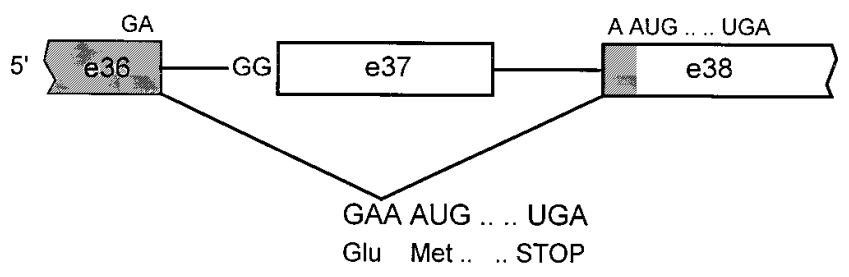

Figure 3. Scheme of exon 37 splicing in normal and $\alpha$ spectrin $^{\text {PRAGUE }}$ allele. Mutation of the acceptor splice site of intron 36 leads to skipping of exon 37. Translation of the mutated mRNA is prematurely terminated at the beginning of exon 38. Rectangles correspond to $\alpha$ spectrin exons, coding region is shaded. Not drawn to scale.

the exon 30-exon 31 boundary. Although the doublet was present in all studied subjects, the proband and his mother had disproportionately increased intensity of the longer alternatively spliced isoform (Fig. 4). To exclude the possibility that the varying intensities were artifacts, we blotted the gel and hybridized it with a probe corresponding to the region of $\alpha$ spectrin gene containing exon 30. Ratios of the two isoforms obtained by densitometric scanning of autoradiographs of Southern blots were consistent with ratios calculated from densitometric tracing of ethidium bromide stained agarose gels.

To identify molecular basis of increased aberrant alternative splicing, we cloned and sequenced the entire intron 30 with adjacent exons from proband's and a control genomic DNA. The sequencing revealed an alternative acceptor splice site located $70 \mathrm{nt}$ upstream from the intron 30-exon 31 boundary and a single point mutation $(\mathrm{C} \rightarrow \mathrm{T})$ introducing an EcoRI restriction site $29 \mathrm{nt}$ upstream from the alternative splice site in one patient's allele (Fig. 5). The insertion of $70 \mathrm{nt}$ in the alternatively spliced mRNA leads to a frameshift and premature termination of translation. In the putative truncated protein 983 amino acid residues from $\alpha$ spectrin $\mathrm{COOH}$ terminus are replaced by 28 new amino acids (EGVWDCTKSLISKHLGSFLFLY-

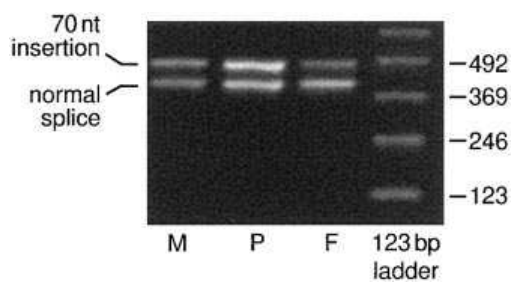

Figure 4. Alternative splicing of intron 30 . PCR amplification of cDNA spanning the exon 30 -exon 31 boundary reveals alternative splicing of intron 30. The shorter band corresponds to the correct isoform and the longer band corresponds to the alternatively spliced isoform with 70 nt insertion. The alternative isoform is significantly stronger in the proband $(P)$ and in his mother $(M)$ than in his father $(F)$.

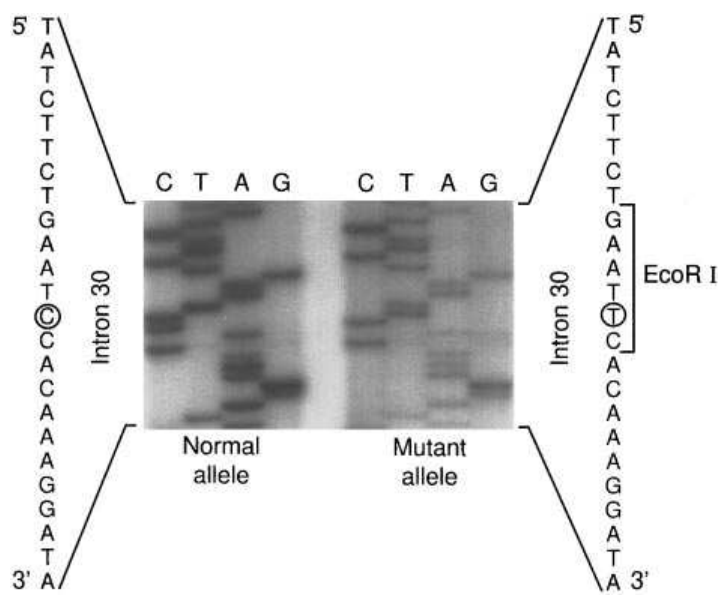

Figure 5. Nucleotide sequence of intron 30 upstream from the alternative acceptor splice site. Sequences of two subclones derived from proband's genomic DNA correspond to the normal $\alpha$ spectrin allele (left) and to the mutated $\alpha$ spectrin ${ }^{\text {LEPRA }}$ allele $(r i g h t)$. The mutated nucleotide in position -99 of intron 30 is circled. The mutation introduces a new EcoRI restriction site into genomic DNA.

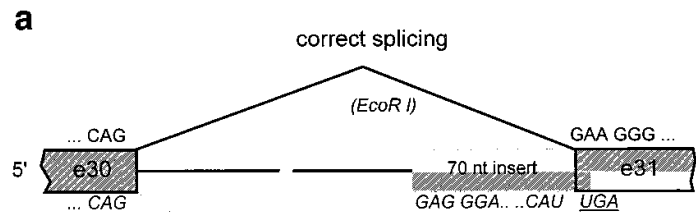

alternative splicing

b

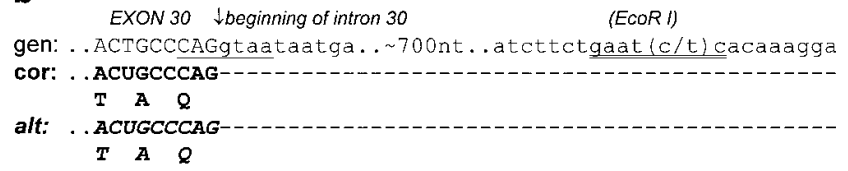
tbeginning of 70 nt insertion taccttcattctttctaggagggagtctgggattgcaccaagagcctaatctccaagca

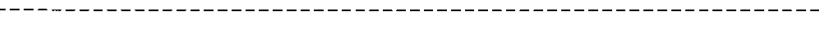
$\begin{array}{lllllllllllllll} & G & V & W & D & C & T & K & S & I & I & S & K & H\end{array}$

Ibeginning of EXON 31

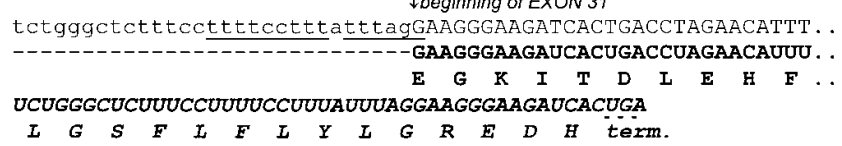

$\begin{array}{lllllllllllllllll}I & G & S & F & I & F & I & Y & L & G & R & E & D & H & \text { term. }\end{array}$

Figure 6. Scheme of the alternative splicing in intron 30. (a) The alternative splicing inserts $70 \mathrm{nt}$ from the $3^{\prime}$ end of intron 30 into the mRNA. Translation of the alternatively spliced mRNA is prematurely terminated. Rectangles correspond to $\alpha$ spectrin exons, shaded boxes are the coding sequences. Position of the mutation enhancing the alternative splicing and introducing EcoRI site in $\alpha$ spectrin $^{\text {LEPRA }}$ is shown by arrow. Alternatively spliced sequence is typed in italic. (b) Nucleotide sequence of parts of intron 30 with neighboring exons corresponding to the genomic DNA (gen), correctly (cor), and alternatively (alt) spliced RNA. Single underlined are nucleotides matching the consensus sequences for splicing, double underlined is the position of the EcoRI restriction site in the $\alpha$ spectrin $^{\text {LEPRA }}$ allele, and dotted underlined is the termination codon in the alternatively spliced RNA. Amino acid sequences were derived from the two mRNA isoforms (one letter coding system). 


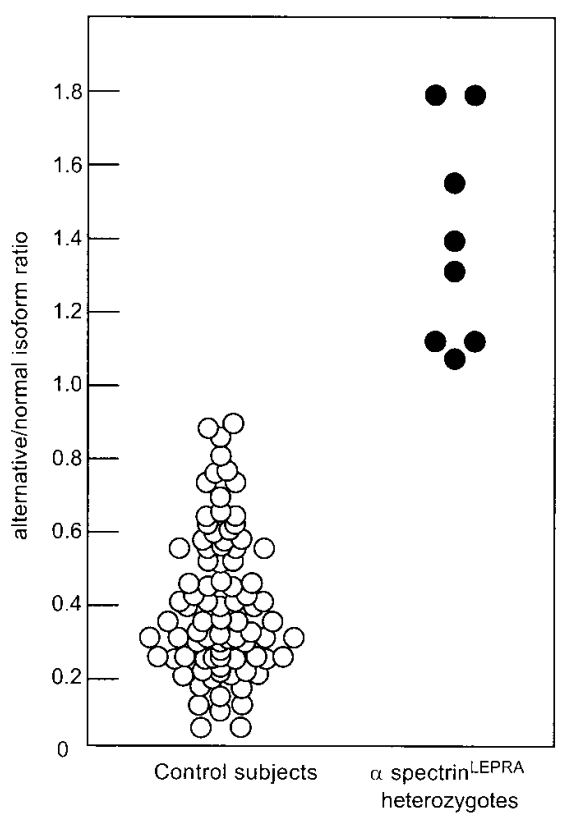

Figure 7. Correlation between the presence of $\alpha^{\text {LEPRA }}$ mutation and increased aberrant alternative splicing in intron 30. cDNA from control subjects was PCR amplified and the ratios of alternatively to correctly spliced mRNA were calculated from densitometric tracing of ethidium bromide-stained agarose gels. Based on screening for the EcoRI site created by the mutation the subjects were divided into two groups: $\alpha$ spectrin homozygotes $(n=86)$ represented by open circles and the $\alpha$ spectrin ${ }^{\text {LEPRA }}$ heterozygotes $(n=8)$ represented by filled circles.

LGREDH). The calculated molecular mass of the aberrant protein is $171 \mathrm{kD}$. The allele carrying the EcoRI mutation was designated as $\alpha$ spectrin $^{\text {LEPRA }}$ (low expression allele Prague). Schematic representation of the correct and alternative splicing together with underlying sequences is shown in Fig. 6.

Screening for aberrant alternative splicing and $\alpha^{\mathrm{LEPRA}}$ mutation. To pursue our hypothesis that the $\alpha^{\text {LEPRA }}$ mutation enhances the alternative acceptor splice site and increases production of the alternatively spliced mRNA, we screened, in addition to the studied family, 91 Czech subjects from 55 families for the ratios of the alternatively to correctly spliced isoform of $\alpha$ spectrin and for the presence of the EcoRI restriction site in intron 30. The studied individuals included both control subjects and patients with autosomal dominant hereditary spherocytosis. We found that six other subjects from four different kindred are heterozygous for the $\alpha^{\text {LEPRA }}$ mutation and have an increased alternative/normal isoform ratio (Fig. 7 and Table III). Screening for the $\alpha$ II mutation by FokI restriction analysis of $3^{\prime}$ region of $\alpha$ II domain revealed that all eight subjects heterozygous for $\alpha^{\text {LEPRA }}$ mutation (including the proband and his mother) were also heterozygous for the $\alpha$ IIa marker. The linkage of the two mutations in the studied family, shown in Fig. 8, was confirmed in two other families in whom we could study a child and both parents.

Study of spectrin synthesis in erythroblasts. PCR amplification of cDNA from the propositus and his parents spanning various polymorphic sites as well as the exon 37 deletion for decreasing number of cycles, allowed us to conclude that there is not a major difference in levels of mRNA produced from individual $\alpha$ spectrin alleles in reticulocytes (data not shown). To
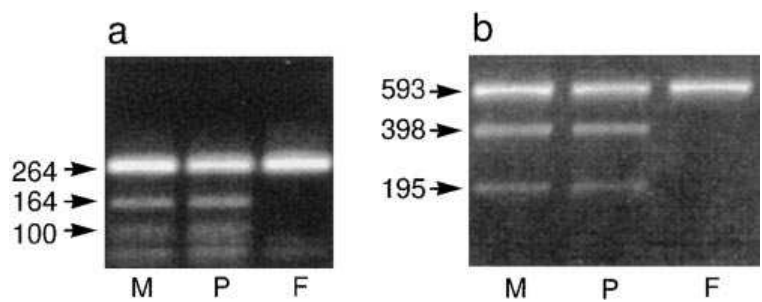

Figure 8. Coinheritance of the $\alpha$ IIa mutation and $\alpha$ spectrin $^{\text {LEPRA }}$ mutation in the proband's family. (a) cDNA prepared from the proband $(P)$, his mother $(M)$, and father $(F)$ was PCR amplified with primers specific for $3^{\prime}$ region of the $\alpha \mathrm{II}$ domain and digested with FokI restriction endonuclease. The 264-bp undigested PCR product corresponds to the common $\alpha$ spectrin allele. The PCR product of $\alpha$ IIa allele is cut with FokI restriction endonuclease into two pieces (164 bp and $100 \mathrm{bp}$ ). (b) EcoRI digest of amplified genomic DNA isolated from the proband and his parents. Normal $\alpha$ spectrin allele produces undigested 593-bp-long fragment. The PCR product of the $\alpha$ spectrin ${ }^{\mathrm{LEPRA}}$ allele is cut with EcoRI restriction endonuclease into two fragments (398 bp and $195 \mathrm{bp}$ ).

determine the ratio of spectrin synthesis, erythroblasts were cultured from peripheral blood of the proband, his parents, and one control subject. Metabolically labeled spectrin was immunoprecipitated from soluble (cytosolic) and insoluble (membrane) fraction and analyzed on SDS-PAGE (Fig. 9). The ratio of $\alpha$ spectrin to $\beta$ spectrin was decreased in cytosolic fractions of both parents (father: 1.06; mother: 1.22 ) to $\sim 50 \%$ of the control ratio (2.16) and strikingly reduced to $10 \%(0.21)$ of the control ratio in the cytosolic fraction from proband's erythroblasts. Careful examination of an overexposed autoradiogram revealed that while no extra band corresponding to the putative alternatively spliced $\alpha$ spectrin ${ }^{\text {LEPRA }}$ was detected in cytosolic fractions of the propositus and his mother, there was a suggestion of a weak band migrating at the position of spectrin $\alpha^{\prime}$ in cytosolic fractions of the propositus and his father. Analysis of membrane fractions from control and proband demonstrated that spectrin is assembled into the membrane skeleton in approximately equimolar amounts (Fig. 9). No truncated $\alpha$ spectrin is detectable in proband's membranes (expected $\sim 4 \%$ of total $\alpha$ spectrin is below the detection limit in the membrane fraction). The rates of $\alpha$ spectrin synthesis are consistent with our hypothesis that both parents have a defect in $\alpha$ spectrin synthesis and that the proband inherited both defective alleles from his parents (Fig. 10).

Table III. Frequency of the $\alpha^{\mathrm{LEPRA}}$ Mutation

\begin{tabular}{lcc}
\hline & Subjects & Families \\
\hline$\alpha / \alpha$ & 85 & 51 \\
$\alpha / \alpha^{\text {LEPRA }}$ & $6^{*}$ & $4^{\ddagger}$ \\
$\alpha^{\text {LEPRA }} / \alpha^{\text {LEPRA }}$ & 0 & 0 \\
$\alpha^{\text {LEPRA }}$ frequency & $3.3 \%$ & $3.6 \%$
\end{tabular}

Subjects included in the screening were either healthy controls or patients with dominant HS. *All six subjects heterozygous for the $\alpha^{\text {LEPRA }}$ mutation were also heterozygous for the $\alpha$ IIa mutation. ${ }^{*}$ In addition to the family of the propositus, the linkage of the $\alpha^{\text {LEPRA }}$ and $\alpha$ IIa mutations was demonstrated in two families where both parents and a child were available for study. 

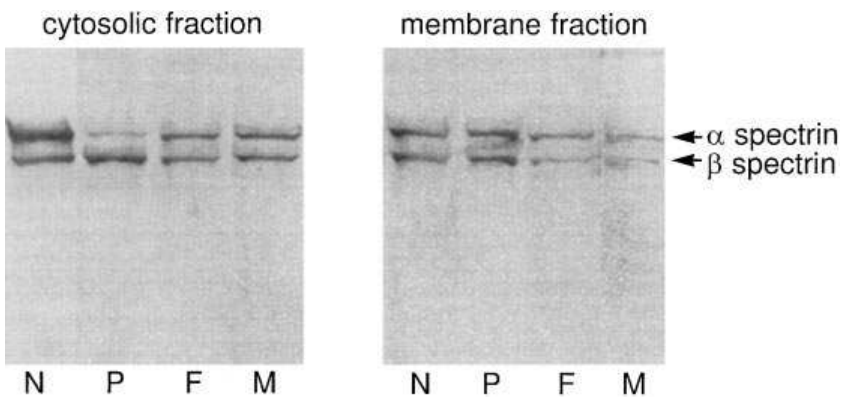

Figure 9. Spectrin synthesis in erythroblasts. Erythroblasts were cultured from peripheral blood from a normal subject $(N)$, the patient $(P)$, and his parents $(F, M)$. Spectrin was immunoprecipitated from soluble (cytosolic) and insoluble (membrane) fractions of metabolically labeled erythroblasts and analyzed on $8 \%$ Laemmli gel. The upper band of the autoradiograph corresponds to $\alpha$ spectrin and the lower band to $\beta$ spectrin.

\section{Discussion}

We studied a patient with severe spherocytic hemolytic anemia without family history of spherocytosis. Spectrin deficiency and the spectrin $\alpha$ II marker detected in one $\alpha$ spectrin allele indicated that this was a case of typical r/ndHS. Identification of an additional truncated $\alpha$ spectrin band in proband's $\mathrm{RBC}$ membrane skeleton suggested that the defect underlying the disease resides in the $\alpha$ spectrin gene.

Analysis of the $3^{\prime}$ region of $\alpha$ spectrin gene revealed a mutation in the penultimate position of intron 36. Mutations of the conserved dinucleotide in the acceptor splice site lead either to use of a cryptic splice site or to skipping of the following exon (42-46). The latter occurs in the mutated allele designated as $\alpha$ spectrin ${ }^{\text {PRAGUE }}$. Skipping of exon 37 from $\alpha$ spectrin mRNA leads to a frameshift and premature termination of translation at the $5^{\prime}$ end of exon 38 . The putative truncated protein corresponds in size to the $\alpha^{\prime}$ spectrin detected in proband's RBC membranes and we propose that the $\alpha^{\prime}$ spectrin is expressed from the $\alpha$ spectrin $^{\text {PRAGUE }}$ allele. Since we detected the same mutation leading to exon 37 skipping in the patient's asymptomatic father, who has no abnormalities in membrane skeleton, we assume that the mutation is recessive.
Presence of apparently normal $\alpha$ spectrin in patient's membranes, which cannot be synthesized from the paternal $\alpha$ spectrin $^{\text {PRAGUE }}$ allele, suggests that the second mutation will reduce expression of the maternal $\alpha$ spectrin allele. One such mutation designated as $\alpha^{\mathrm{LELY}}$ was recently discovered by Wilmotte and colleagues in the $\alpha$ spectrin nucleation site (47). Analysis of the nucleation site, however, revealed that none of the family members carries the $\alpha^{\text {LELY }}$ mutation. Search for the potential maternal defect brought to our attention alternative splicing in intron 30 of the $\alpha$ spectrin gene. Splicing of intron 30 can proceed either normally by using the regular acceptor splice site and producing a normal mRNA transcript or alternatively by using a conserved alternative acceptor splice site detected $70 \mathrm{nt}$ upstream from the regular site. The alternatively processed $\alpha$ spectrin mRNA retains the last $70 \mathrm{nt}$ from the 3 '-end of intron 30, which causes a frameshift and leads to premature termination of translation in exon 31.

While most of the studied control subjects used predominantly the regular splice site, the patient, his mother, and several other subjects produced more of the alternative isoform. We identified a mutation $29 \mathrm{nt}$ upstream from the alternative splice site which is linked to the observed increase in alternative splicing. Since this mutation does not involve any of the known conserved splicing sequences, we suggest that it causes a structural change in pre-mRNA, making the alternative acceptor splice site more accessible for a spliceosome. We designate the maternal allele carrying the mutation $\alpha$ spectrin $^{\text {LEPRA }}$.

Based on results obtained from metabolic labeling of erythroblasts, we calculated that the $\alpha$ spectrin ${ }^{\text {LEPRA }}$ allele produces only $\sim 1 / 5$ of full-length spectrin as compared with the normal $\alpha$ spectrin allele. Similarly, assuming that the transcription of $\alpha$ spectrin gene and the stability of the two mRNA isoforms are comparable, we can calculate, based on the average ratio of alternative to correct isoform in the normal $\alpha$ spectrin homozygotes $(0.4)$ and the average ratio in the $\alpha$ spectrin $^{\text {LEPRA }}$ heterozygotes (1.4), that the $\alpha$ spectrin ${ }^{\text {LEPRA }}$ allele produces only $\sim 1 / 6$ of the correctly spliced isoform as compared with the normal $\alpha$ spectrin allele. Our hypothesis that the $\alpha^{\text {LEPRA }}$ mutation is the actual defect involved in the disease is further supported by our discovery of a linkage between the $\alpha^{\text {LEPRA }}$ mutation and the $\alpha \mathrm{II}$ a polymorphism that was shown to be a marker in $\sim 50 \%$ cases of $\mathrm{r} / \mathrm{ndHS}(25-27)$. We conclude that

\section{FATHER}

MOTHER

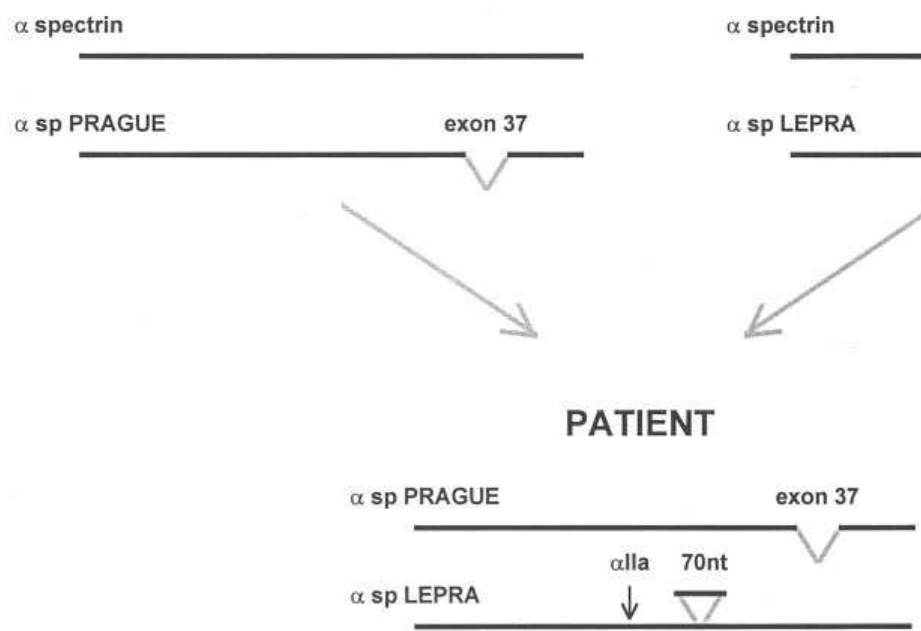

Figure 10. Scheme of inheritance of the two defects in the studied family. The subject is a compound heterozygote with two recessive mutations inherited from his parents. $\alpha$ spectrinLEPRA allele, which inserts with higher frequency $70 \mathrm{nt}$ from intron 30 into mRNA, was inherited from his mother, and $\alpha$ spectrin $^{\text {PRAGUE }}$ allele, which skips exon 37 from mRNA, was inherited from his father. 
the $\alpha^{\text {LEPRA }}$ mutation combined in trans with the $\alpha^{\text {PRAGUE }}$ mutation, are the two defects underlying patient's phenotype.

Spectrin synthesized in avian erythrocytes exists in four different forms: $\alpha$ homodimers, $\beta$ homotetramers, $\alpha / \beta$ heterodimers, and $\alpha / \beta$ heterotetramers (48). The $\alpha$ homodimer form is turned over with a half-life of $2 \mathrm{~h}$ (49). Our results from metabolic labeling of human erythroblasts suggest that truncated $\alpha$ spectrin proteins lacking the nucleation site are rapidly turned over with half-lives undetectable by standard pulsechase experiment. Thus, it is likely that $\alpha$ spectrin missing the $\mathrm{COOH}$ terminus will be produced as a highly unstable monomeric $\alpha$ spectrin, which will be degraded by a fast pathway distinct from the degradation of dimeric species. The fact that we were able to detect some truncated $\alpha$ spectrin produced from the paternal $\alpha$ spectrin $^{\text {PRAGUE }}$ allele in patient's RBC membrane skeleton indicates that even though the protein lacks the entire nucleation site, it still retains a limited ability to bind $\beta$ spectrin. The rate of this binding is probably much slower than heterodimerization of normal $\alpha$ spectrin; therefore, the truncated protein can only be detected in the $\alpha$ spectrin-deficient environment of patient's erythrocytes. On the other hand, the notably shorter $\alpha$ spectrin produced from the maternal allele is not detectable even in patient's membrane skeleton indicating that the protein completely lost its ability to heterodimerize with $\beta$ spectrin.

The amount of mammalian $\alpha$ spectrin synthesized during in vitro erythroid differentiation considerably exceeds that of $\beta$ spectrin $(30,31)$. Consequently, a complete knockout of one $\alpha$ spectrin allele should not lead to a detectable spectrin deficiency, since one $\alpha$ spectrin allele would produce enough protein to associate with the available $\beta$ spectrin. Our results prove this hypothesis by demonstrating the absence of the protein product of one $\alpha$ allele in the asymptomatic father of the propositus and by showing that an additional mutation in the other $\alpha$ spectrin allele is needed to produce a clinically apparent phenotype.

We propose that $\alpha$ spectrin $^{\text {LEPRA }}$ might represent a widespread allele involved in pathogenesis of spectrin deficient, recessive, or nondominant HS. Based on the reported frequency of $\alpha$ IIa polymorphism in families with $\mathrm{r} / \mathrm{nd} \mathrm{HS}$ (26), we expect that $\sim 50 \%$ of subjects with this phenotype will be either $\alpha$ spectrin $^{\text {LEPRA }}$ homozygotes or compound heterozygotes with another $\alpha$ spectrin defect found in trans with $\alpha$ spectrin $^{\text {LEPRA. }}$. To address this hypothesis we are currently analyzing patients carrying the $\alpha$ IIa mutation for the presence of the $\alpha^{\text {LEPRA }}$ mutation and for aberrant alternative splicing.

\section{Acknowledgments}

We thank Drs. Vaclav Brabec and Kveta Petrtylova for help with obtaining blood samples, Mr. Hillard L. Rubin and Ms. Iva Smockova for help with some of the experiments, and Ms. Donna-Marie Mironchuk for preparation of the figures.

This work was supported by National Institutes of Health grants HL-37462 and HL-27215 to J. Palek.

\section{References}

1. Jarolim, P., H.L. Rubin, S. Liu, M.R. Cho, V. Brabec, L.H. Derick, S.J. Yi, S.T.O. Saad, S. Alper, C. Brugnara et al. 1994. Duplication of 10 nucleotides in the erythroid band 3 (AE1) gene in a kindred with hereditary spherocytosis and band 3 protein deficiency (band $3^{\text {PRAGUE}) . ~ J . ~ C l i n . ~ I n v e s t . ~ 93: 121-130 . ~}$

2. Jarolim, P., H.L. Rubin, V. Brabec, L. Chrobak, A.S. Zolotarev, S.L.
Alper, C. Brugnara, H. Wichterle, and J. Palek. 1995. Mutations of conserved arginines in the membrane domain of erythroid band 3 protein lead to a decrease in membrane-associated band 3 and to the phenotype of hereditary spherocytosis. Blood. 85:634-640.

3. Jarolim, P., J. Palek, H.L. Rubin, J.T. Prchal, C. Korsgren, and C.M. Cohen. 1992. Band 3 Tuscaloosa: $\operatorname{Pro}^{327} \rightarrow \mathrm{Arg}^{327}$ substitution in the cytoplasmic domain of erythrocyte band 3 protein associated with spherocytic hemolytic anemia and partial deficiency of protein 4.2. Blood. 80:523-529.

4. Rybicki, A.C., J.J.H. Qiu, S. Musto, N.L. Rosen, R.L. Nagel, and R.S Schwartz. 1993. Human erythrocyte protein 4.2 deficiency associated with hemolytic anemia and a homozygous ${ }^{40}$ glutamic acid $\rightarrow$ lysine substitution in the cytoplasmic domain of band 3 (Band $3^{\text {Montefiore) }}$. Blood. 81:2155-2165.

5. Jenkins, P.A., G.K. Abou-Alfa, D. Dhermy, E. Bursaux, C. Feo, A.L. Scarpa, S.E. Lux, M. Garbarz, B.G. Forget, and P.G. Gallagher. 1996. A nonsense mutation in the erythrocyte band 3 gene associated with decreased mRNA accumulation in a kindred with dominant hereditary spherocytosis. $J$. Clin. Invest. 97:373-380.

6. Maillet, P., A. Vallier, W.H. Reinhart, E.J. Wyss, P. Ott, P. Texier, F. Baklouti, M.J.A. Tanner, J. Delaunay, and N. Alloisio. 1995. Band 3 Chur: a variant associated with band 3-deficient hereditary spherocytosis and substitution in a highly conserved position of transmembrane segment 11. Br. J. Haematol. 91:804-810.

7. Eber, S.W., J.M. Gonzalez, M.L. Lux, A.L. Scarpa, W.T. Tse, M. Dornwell, J. Herbers, W. Kugler, R. Ozcan, A. Pekrun et al. 1996. Ankyrin-1 mutations are a major cause of dominant and recessive hereditary spherocytosis. $\mathrm{Na}$ ture Genet. 13:214-218.

8. Lux, S.E., W.T. Tse, J.C. Menninger, K.M. John, P. Harris, O. Shalev, R.R. Chilcote, S.L. Marchesi, P.C. Watkins, V. Bennett et al. 1990. Hereditary spherocytosis associated with deletion of human erythrocyte ankyrin gene on chromosome 8. Nature (Lond.). 345:736-739.

9. Jarolim, P., H.L. Rubin, V. Brabec, and J. Palek. 1995. A nonsense mutation 1669 Glu $\rightarrow$ Ter within the regulatory domain of human erythroid ankyrin leads to a selective deficiency of the major ankyrin isoform (band 2.1) and a phenotype of autosomal dominant hereditary spherocytosis. J. Clin. Invest. 94: 941-947.

10. Jarolim, P., H.L. Rubin, V. Brabec, and J. Palek. 1993. Abnormal alternative splicing of erythroid ankyrin mRNA in two kindred with hereditary spherocytosis (ankyrin ${ }^{\text {PRAGUE }}$ and ankyrin ${ }^{\text {RAKOVNIK }}$ ). Blood. 82:4a. (Abstr.)

11. Becker, P.S., W.T. Tse, S.E. Lux, and B.G. Forget. 1993. $\beta$ spectrin Kissimmee: a spectrin variant associated with autosomal dominant hereditary spherocytosis and defective binding to protein 4.1. J. Clin. Invest. 92:612-616.

12. Jarolim, P., H. Wichterle, M. Hanspal, J. Murray, H.L. Rubin, and J.

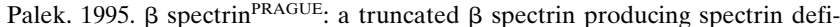
ciency, defective spectrin heterodimer self-association and a phenotype of spherocytic elliptocytosis. Br. J. Haematol. 91:502-510.

13. Hassoun, H., J.N. Vassiliadis, J. Murray, S.J. Yi, M. Hanspal, R.E. Ware, S.S. Winter, S.S. Chiou, and J. Palek. 1995. Molecular basis of spectrin deficiency in $\beta$ spectrin Durham: a deletion within $\beta$ spectrin adjacent to the ankyrin-binding site precludes spectrin attachment to the membrane in hereditary spherocytosis. J. Clin. Invest. 96:2623-2629.

14. Hassoun, H., J.N. Vassiliadis, J. Murray, F. Schaffer, P. Jarolim, S.K. Ballas, V. Brabec, and J. Palek. 1995. Characterization of the underlying molecular defect in hereditary spherocytosis associated with spectrin deficiency. Blood. 86(Suppl. 1):467a. (Abstr.)

15. Hassoun, H., J.N. Vassiliadis, J. Murray, S.J. Yi, M. Hanspal, C.A Johnson, and J. Palek. 1996. Hereditary spherocytosis with spectrin deficiency due to an unstable truncated beta spectrin. Blood. 87:2538-2545.

16. Bouhassira, E.E., R.S. Schwartz, Y. Yawata, K. Ata, A. Kanzaki, J.J.-H. Qiu, R.L. Nagel, and A.C. Rybicki. 1992. An alanine-to-threonine substitution in protein 4.2 cDNA associated with a Japanese form of hereditary hemolytic anemia (protein 4.2 $2^{\mathrm{NIPON}}$ ). Blood. 79:1846-1854.

17. Takaoka, Y., H. Ideguchi, M. Matsuda, N. Sakamoto, T. Takeuchi, and Y. Fukumaki. 1994. A novel mutation in the erythrocyte protein 4.2 gene of Japanese patients with hereditary spherocytosis (protein 4.2 ${ }^{\text {Fukuoka }}$ ). Br. J. Haematol. 88:527-533.

18. Hayette, S., D. Dhermy, M.E. Dossantos, M. Bozon, D. Drenckhahn, N. Alloisio, P. Texier, J. Delaunay, and L. Morle. 1995. A deletional frameshift mutation in protein 4.2 gene (allele 4.2 Lisboa) associated with hereditary hemolytic anemia. Blood. 85:250-256.

19. Hayette, S., L. Morle, M. Bozon, A. Ghanem, M. Risinger, C. Korsgren, M.J.A. Tanner, S. Fattoum, C.M. Cohen, and J. Delaunay. 1995. A point mutation in the protein 4.2 gene (allele 4.2 Tozeur) associated with hereditary haemolytic anaemia. Br. J. Haematol. 89:762-770.

20. Matsuda, M., N. Hatano, H. Ideguchi, H. Takahira, and Y. Fukumaki. 1995. A novel mutation causing an aberrant splicing in the protein 4.2 gene associated with hereditary spherocytosis (protein $4.2^{\text {Notame }}$ ). Hum. Mol. Genet. 4: 1187-1191.

21. Agre, P., E.P. Orringer, and V. Bennett. 1982. Deficient red-cell spectrin in severe, recessively inherited spherocytosis. N. Engl. J. Med. 306:11551161.

22. Agre, P., J.F. Casella, W.H. Zinkham, C. McMillan, and V. Bennett. 1985. Partial deficiency of erythrocyte spectrin in hereditary spherocytosis. $\mathrm{Na}$ - 
ture (Lond.). 314:380-383.

23. Whitfield, C.F., J.B. Follweiler, L. Lopresti-Morrow, and B.A. Miller. 1991. Deficiency of $\alpha$-spectrin synthesis in burst-forming units-erythroid in lethal hereditary spherocytosis. Blood. 78:3043-3051.

24. Winkelmann, J.C., S.L. Marchesi, P. Watkins, A.J. Linnenbach, P. Agre, and B.G. Forget. 1986. Recessive hereditary spherocytosis is associated with an abnormal alpha spectrin subunit. Clin. Res. 34:474a. (Abstr.)

25. Marchesi, S.L., P. Agre, and D.W. Speicher. 1989. Abnormal spectrin aII domain in recessive spherocytosis. J. Cell Biochem. 13B:213. (Abstr.)

26. Marchesi, S.L., P. Agre, D.W. Speicher, W.T. Tse, and B.G. Forget. 1989. Mutant spectrin $\alpha$ II domain in recessively inherited spherocytosis. Blood. 74(Suppl. 1):182a. (Abstr.)

27. Boivin, P., C. Galand, I. Devaux, M.C. Lecomte, M. Garbarz, and D. Dhermy. 1993. Spectrin $\alpha$ IIa variant in dominant and non-dominant spherocytosis. Hum. Genet. 92:153-156.

28. Gallagher, P.G., and B.G. Forget. 1993. Spectrin genes in health and disease. Semin. Hematol. 30:4-21.

29. Speicher, D.W., L. Weglarz, and T.M. Desilva. 1992. Properties of human red cell spectrin heterodimer (side-to-side) assembly and identification of an essential nucleation site. J. Biol. Chem. 267:14775-14782.

30. Hanspal, M., J.S. Hanspal, R. Kalraiya, S.C. Liu, K.E. Sahr, D. Howard, and J. Palek. 1992. Asynchronous synthesis of membrane skeletal proteins during terminal maturation of murine erythroblasts. Blood. 80:530-539.

31. Hanspal, M., and J. Palek. 1987. Synthesis and assembly of membrane skeletal proteins in mammalian red cell precursors. J. Cell Biol. 105:1417-1424

32. Dodge, J.T., C. Mitchell, and D.J. Hanahan. 1963. The preparation and chemical characteristics of hemoglobin-free ghosts of human erythrocytes. Arch. Biochem. Biophys. 100:119-130.

33. Fairbanks, G., T.L. Steck, and D.F.H. Wallach. 1971. Electrophoretic analysis of the major polypeptides of the human erythrocyte membrane. Biochemistry. 10:2606-2617.

34. Laemmli, U.K. 1970. Cleavage of structural proteins during the assembly of the head of bacteriophage T4. Nature (Lond.). 227:680-685.

35. Jennings, L.K., L.K. Brown, and M.E. Dockter. 1985. Quantitation of protein 3 content of circulating erythrocytes at the single-cell level. Blood. 65 : $1256-1262$.

36. Liu, S., J. Palek, J. Prchal, and R.P. Castleberry. 1981. Altered spectrin dimer-dimer association and instability of erythrocyte membrane skeletons in hereditary pyropoikilocytosis. J. Clin. Invest. 68:597-605.

37. Goosens, M., and Y.W. Kan. 1981. DNA analysis in the diagnosis of hemoglobin disorders. Methods Enzymol. 76:805-817.
38. Sahr, K., T. Tobe, A. Scarpa, K. Laughinghouse, S.L. Marchesi, P. Agre, A.J. Linnenbach, V.T. Marchesi, and B.G. Forget. 1989. Sequence and exonintron organization of the DNA encoding the aI domain of human spectrin. Application to the study of mutations causing hereditary elliptocytosis. J. Clin. Invest. 84:1243-1252.

39. Sykes, B.G. 1983. DNA in heritable disease. Lancet. ii:787-788.

40. Orita, M., H. Iwahana, H. Kanazawa, K. Hayashi, and T. Sekiya. 1989. Detection of polymorphisms of human DNA by gel electrophoresis as singlestrand conformation polymorphisms. Proc. Natl. Acad. Sci. USA. 86:2766-2770.

41. Hanspal, M., J.S. Hanspal, K.E. Sahr, E. Fibach, J. Nachman, and J. Palek. 1993. Molecular basis of spectrin deficiency in hereditary pyropoikilocytosis. Blood. 82:1652-1660.

42. Mount, S.M. 1982. A catalogue of splice junction sequences. Nucleic Acids Res. 10:459-472.

43. Baklouti, F., J. Maréchal, R. Wilmotte, N. Alloisio, L. Morlé, M. T. Ducluzeau, L. Denoroy, A. Mrad, M.H. Ben Aribia, and R. Kastally. 1992. Elliptocytogenic $\alpha^{1 / 36}$ spectrin Sfax lacks nine amino acids in helix 3 of repeat 4 . Evidence for the activation of a cryptic $5^{\prime}$-splice site in exon 8 of spectrin $\alpha$-gene. Blood. 79:2464-2470.

44. Gallagher, P.G., W.T. Tse, F. Costa, A. Scarpa, P. Boivin, J. Delaunay, and B.G. Forget. 1991. A splice site mutation of the $\beta$-spectrin gene causing exon skipping in hereditary elliptocytosis associated with a truncated $\beta$-spectrin chain. J. Biol. Chem. 266:15154-15159.

45. Alloisio, N., R. Wilmotte, J. Maréchal, P. Texier, L. Denoroy, C. Féo, Z Benhadji-Zouaoui, and J. Delaunay. 1993. A splice site mutation of $\alpha$-spectrin gene causing skipping of exon 18 in hereditary elliptocytosis. Blood. 81:27912798.

46. Hennig, E.E., A.H. Conney, and S.J. Wei. 1995. Characterization of hpr splicing mutations induced by the ultimate carcinogeni metabolite of benzo[a]pyrene in Chinese hamster V-79 cells. Cancer Res. 55:1550-1558.

47. Wilmotte, R., J. Maréchal, L. Morlé, F. Baklouti, N. Philippe, R. Kastally, L. Kotula, J. Delaunay, and N. Alloisio. 1993. Low expression allele $\alpha^{\text {LELY }}$ od red cell spectrin is associated with mutations in exon $40\left(\alpha^{\mathrm{V} / 41}\right.$ polymorphism) and intron 45 and with partial skipping of exon 46. J. Clin. Invest. 91: 2091-2096.

48. Woods, C.M., and E. Lazarides. 1986. Spectrin assembly in avian erythroid development is determined by competing reactions of subunit homo- and heterodimers. Nature (Lond.). 321:85-89.

49. Woods, C.M., and E. Lazarides. 1985. Degradation of unassembled aand $\beta$-spectrin by distinct intracellular pathways: regulation of spectrin topogenesis by $\beta$-spectrin degradation. Cell. 40:959-969. 